\title{
Probiotic-Based Nutritional Effects on Killifish Reproduction
}

\author{
F Lombardo, G Gioacchini, 0 Carnevali* \\ Dipartimento di Scienze della Vita e dell'Ambiente, Università Politecnica delle Marche \\ via Brecce Bianche, 60131 Ancona - Italy. \\ *Correspondence to: Oliana Carnevali, o.carnevali@univpm.it
}

Abstract

Accepted: October 12, 2011; Published: November 11, 2011

\begin{abstract}
Probiotic bacteria used as dietary additives seem to offer an attractive choice inducing overall health benefits to the host organism. It is well known that reproduction, in all vertebrates, is regulated by the reproductive axis and that nutrition affects reproductive events, from puberty to adult gametogenesis, in both sexes. Consequently, reproductive events are very closely aligned with the nutrition. The aims of this study were to investigate the effects of dietary probiotic administration on the marine teleost Fundulus heteroclitus and the effects of such broodstock dietary treatment on the growth and survival of the new progeny. Lactobacillus rhamnosus IMC $501 \circledast^{\circledR}$ was administered daily as a feed additive, at a final concentration of $10^{6} \mathrm{cfu} \mathrm{ml}^{-1}$ for 8 days. Gonadal growth (gonadosomatic index, GSI), fecundity, embryo survival and hatching rate of larvae from broodstock fed probiotic-supplemented diets were analysed as well as the biometric parameters (body weight, BW; total length, TL). The results demonstrated the beneficial effects of probiotics on the reproductive performance of this marine teleost, as the GSI, fecundity and embryo survival were significantly enhanced by probiotic administration. On the contrary, no effect on the hatching rate was shown. Moreover, broodstock probiotic-based nutrition affected the early stages of larval development of the new progeny: in detail, a significantly higher TL was shown throughout the experiment in the progeny derived from the probiotic (PRO) group bloodstocks compared to the control (CTRL) group; mean BW was significantly higher only at 30 days post-hatching (dph) while no change was observed in terms of larval survival. These results confirmed the positive effect of L. rhamnosus IMC 501 @on the reproductive process of this marine teleost, but further work is required to better understand the mechanisms by which probiotics act on the reproductive axis as well as the nutritionally-/immunologically-mediated maternal effects on embryo and larval development and growth.
\end{abstract}

Keywords: Fundulus heteroclitus; Lactobacillus rhamnosus; egg quality; fish larvae.

\section{Introduction}

In all vertebrates, reproductive functions are regulated by the interplay of the three major glands: hypothalamus, pituitary and gonads which form the so-called 'HPG' or reproductive axis 'RA' [1]. Correct function of the HPG axis, and hence reproductive capacity, other than environmental factors, is gated by metabolic and nutritional factors [2]. The consequences of nutrition on reproduction are well known and widely reported. Nutrition affects all aspects of reproductive events, from pubescence to gametogenesis, in both males and females. This close association between nutrition and reproduction is to guarantee that reproductive events are very intimately aligned with the nutrient supply [3] in order to ensure survival of the new progeny.

In many reared teleost species, especially in those new to aquaculture, unsettled and variable reproductive performances are important restrictive factors for the successful mass production of fry. An improvement in broodstock nutrition and alimentation has been shown to greatly enhance gamete quality and likewise offspring production, because peculiar essential dietary nutrients affect gonadal development and fecundity, particularly in continuous spawners with short vitellogenesis [4].

Nowadays, fish aquaculture represents a growing proportion of animal proteins [5] but rearing conditions, especially in intensive fish farming installations with high stocking densities and high nutrient inputs, can elicit selection for and multiplication of opportunistic bacteria [6]. The extensive employment of drugs, antibiotics, pesticides and antiseptics to prevent bacterial diseases and to promote juvenile growth has led to the development of resistant bacterial strains and subsequent potential safety issues [7]. The global increase in bacterial resistance to antibiotics [8] has increased research into the usage of probiotics, since, when exogenously supplied, probiotics can exert benefits on host welfare other than nutritional support [9]. By 


\section{Research Article}

definition, probiotics are "live micro-organisms which when administered in adequate amounts confer a health benefit on the host" [10]. Many bacteria have been selected as probiotic bacteria useful for growth or larval improvement in aquatic species [11-15] and many studies have reported improved disease resistances [16] and stronger immune responses [17] in fish fed a diet containing living probiotic bacteria. However, the mechanisms of probiotic action are far from totally understood, although it is broadly accepted in the literature that they can benefit the host animal by producing inhibitory compounds, competing against pathogenic bacteria for nutrients and adhesion sites, improving the microbial balance and modulating the immune system physiology [18].

Despite the increasing interest in probiotic use in the fish farming industry, studies concerning their effects on teleost or other vertebrate reproduction are very scarce. To our knowledge, only a few studies [19-21] have investigated the beneficial effects of probiotics dietary supplementation on the reproductive performance (GSI, fecundity, fry production, BW and TL of fry) of four live bearing ornamental species (Poecilia reticulata, P. sphenops, Xiphophorus helleri, X. maculatus). Their results have been complemented by the findings obtained by Gioacchini et al. [15] concerning the effects of dietary probiotics on the endocrine control of Danio rerio reproduction as well as on the auto/paracrine factors involved in the regulation of oocyte maturation; in particular, L. rhamnosus IM C $501{ }^{\circledR}$ strain induced changes in the brain, gut and ovary at the molecular level as well as an in vitro maturation assays which revealed a higher rate of germinal vesicle break down (GVBD) in oocytes derived from females fed the probiotic diet.

Based on this information, the aims of this study were to investigate the effects of probiotic dietary administration on the reproductive performances of the marine teleost Fundulus heteroclitus and the effects of such broodstock dietary treatment on the growth and survival of new progeny.

\section{Methods}

\subsection{Fish}

The killifish Fundulus heteroclitus (Cyprinodontidae), obtained from a commercial supplier (Fauna M arina S.L., Cadiz - Spain), is an euryhaline oviparous teleost that in nature displays semi-lunar spawning cycles synchronized with new and full moon tides [22]. Such a semi-lunar pattern of reproduction is free-running under proper laboratory conditions and can be monitored by daily egg collection or regular ovarian sampling $[23,24]$. Thanks to its appropriate size and its easily laboratory reproduction, this species can be utilized as an excellent research fish model for studying the endocrine control of reproductive cycles in teleosts [25]. Adult killifish ( $\mathrm{TL}=70-90 \mathrm{~mm}$ ), maintained in $100 \mathrm{~L}$ tanks under controlled condition $\left(24^{\circ} \mathrm{C} ; 14 \mathrm{~L} / 10 \mathrm{D}, 30 \%\right.$ ), were fed ad libitum with a commercial diet (Tetramin $®$, Tetra, M elle, Germany) twice a day.

\subsection{Probiotic strain}

The probiotic strain used in this study was Lactobacillus rhamnosus IMC $501 @$, supplied by Synbiotec S.r.l., Camerino - Italy. It was administrated daily at $10^{6} \mathrm{cfu} \mathrm{m}^{-1}$ as suggested by the producer. This probiotic strain was selected since it is a common constituent of the human indigenous microbiota present in the intestinal and urogenital tracts and it is able to balance the intestinal microbiota, inducing host immune-modulation and decreasing the symptoms of a wide range of gastrointestinal disorders [26-28].

\subsection{Exposure and rearing conditions}

Ten pairs of adult killifish ( $T \mathrm{~L}=70-90 \mathrm{~mm}$ ) were maintained for 8 days in separate $10 \mathrm{~L}$ spawning tanks, with a sex ratio of 1 female/ 1 male. In addition, the spawning tanks were equipped with a plastic vertical net $(5 \mathrm{~mm}$ mesh diameter), since these fishes tend to spawn against the screen [24]. Two experimental groups were set up: a control group (CTRL) fed commercial diet and a treated group (PRO) fed the commercial diet supplemented with L. rhamnosus IM C 501 \& The experiment was repeated three times and all procedures were performed in accordance with the guidelines on the handling and training of laboratory animals by the Universities Federation for Animal Welfare (UFAW) and with the Italian animal welfare legislation (D.L. 116/92). 


\subsubsection{Killifish gonadosomatic index (GSI) assessment}

After 8 days, 5 female broodstocks from each experimental group (CTRL and PRO) were captured by netting and sacrificed by a lethal overdose of anaesthesia $(500 \mathrm{mg} / \mathrm{L} \mathrm{MS}-222$ [3-aminobenzoic acid ethyl ester] buffered to $\mathrm{pH}$ 7.4; Sigma). Total wet body weight $(\mathrm{mg})$ and ovary weight $(\mathrm{mg})$ were recorded. To quantify gonadal growth in females, the single ovary (a fusion of two lobes) of each fish was removed, weighed (to the nearest $0.1 \mathrm{mg}$ ) and the GSI calculated by expressing the gonad weight as a percentage of the total body weight.

\subsubsection{Killifish fecundity assessment}

Fecundity, expressed as mean number of daily eggs spawned by each experimental group, was daily assessed at 10 a.m. by siphoning out the spawning tank bottom. During 8 days of treatment, embryos were manually counted and used for subsequently embryo survival assay.

\subsubsection{Killifish embryo survival and hatching rate assessment}

Thanks to the capability of killifish embryos to undergo an aerial development, the fertilized eggs from CTRL and PRO groups were deposited on a piece of blotting paper in a $90 \mathrm{~mm}$ plastic Petri plate moistened with $30 \%$ artificial seawater and incubated at room temperature $\left(24^{\circ} \mathrm{C}\right)$ for 8 days. Embryo survival (expressed as mean of live embryos by each experimental group) and hatching rate (calculated as the percentage of number of viable larvae after hatching, divided by the number of fertilized eggs) were monitored until hatching occurred at $8 \mathrm{dpf}$ (days post-fertilization).

\subsection{Killifish progeny biometric parameters assessment}

To assess the potential beneficial health effects of broodstock probiotic-based nutrition, $50 \pm 2$ larvae ( 3 replicates each), hatched from CTRL and PRO groups were reared in $5 \mathrm{~L}$ tanks for a period of 30 days. Both groups were maintained in the same rearing condition as the broodstocks and fed with Artemia salina nauplii (at 9 a.m.) and commercial dry diet (Tetramin $®$, Tetra, Melle, Germany) (at 5 p.m.). Larval survival was monitored during the experiment and larval biometrical parameters, such as BW (mg) and TL $(\mathrm{mm})$, were recorded during sampling at day 0 (start), 10, 20 and 30 (end) post hatching (dph). At each sampling, 10 larvae from each experimental group were captured by netting and sacrificed by a lethal overdose of anaesthesia ( 500 $\mathrm{mg} / \mathrm{L} \mathrm{MS}$-222 [3-aminobenzoic acid ethyl ester] buffered to pH 7.4; Sigma), dried on blotting paper and weighed using an analytical balance accurate to $0.1 \mathrm{mg}$ (OHAUS Explorer E11140). Subsequently, larvae were measured in length using a sliding micrometer microscope (STEM I 2000).

\subsection{Statistical analysis}

All data are presented as mean \pm SD. One-way ANOVA followed by Bonferroni's multiple comparison test was used for comparison between each experimental group using a statistical software package, GraphPad Prism (GraphPad Software Inc., USA). Asterisks or different letters in the figures denote significant differences from the control group $(P<0.05)$.

\section{Results}

\subsection{Probiotic effects on killifish GSI and fecundity}

In this study, a significantly higher GSI was found in females fed probiotic-supplemented diet when compared with females fed control diet $(P<0.05)$ (Figure 1). In addition, PRO group also showed a significantly higher fecundity in terms of mean number of eggs spawned by each experimental group when compared to the CRTL group $(P<0.05)$ (Figure 2$)$. 


\section{Research Article}

Figure 1: Killifish gonadosomatic index (GSI). CTRL: females fed control diet; PRO: females fed L. rhamnosus IMC 501@supplemented diet.

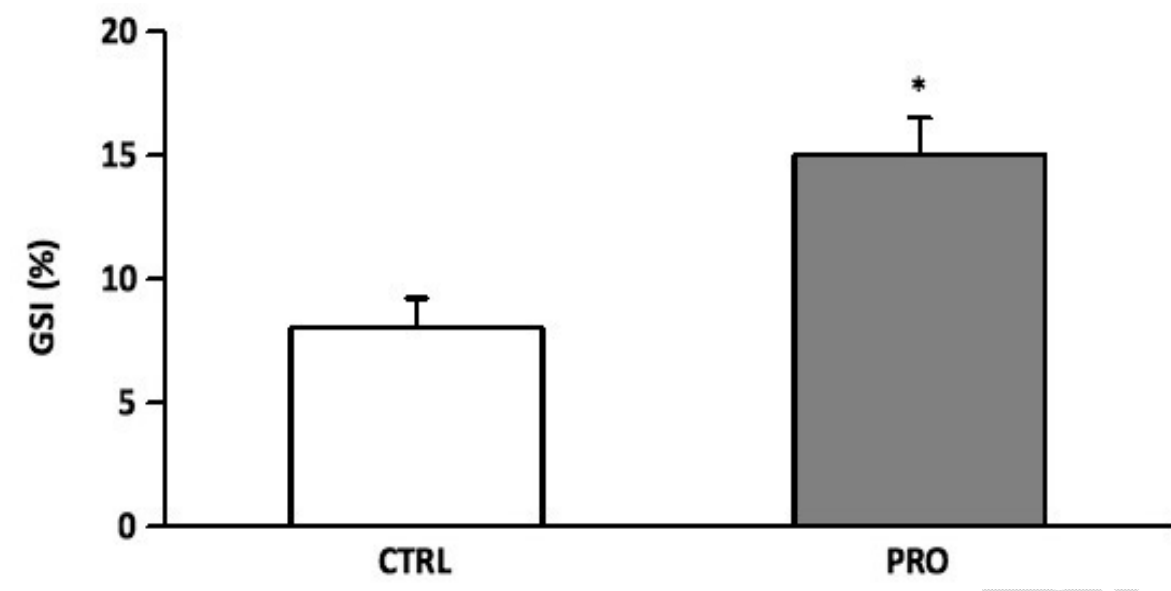

Figure 2: Killifish mean fecundity. CTRL: females fed control diet; PRO: females fed L. rhamnosus IM C $501 \AA$ supplemented diet.

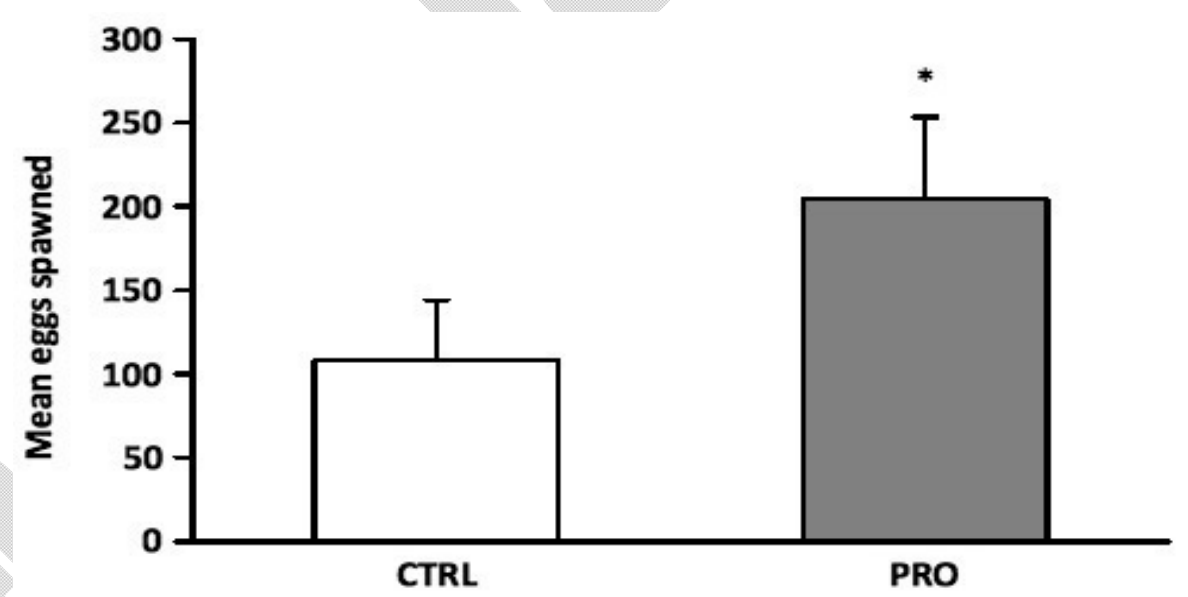

\subsection{Probiotic effects on killifish embryo survival and hatching rate}

Killifish embryo survival, calculated at $8 \mathrm{dpf}$, was significantly enhanced by probiotic-supplemented diet when compared to control group $(\mathrm{P}<0.05)$ (Figure 3 ), while the hatching rate, at $8 \mathrm{dpf}$, was not affected by probiotic dietary administration $(P>0.05)$ (Figure 4). 
Figure 3: Killifish mean embryo survival. CTRL: embryos from fish fed commercial diet; PRO: embryos from fish fed probiotic (L. rhamnosus IM C 501@)-supplemented diet.

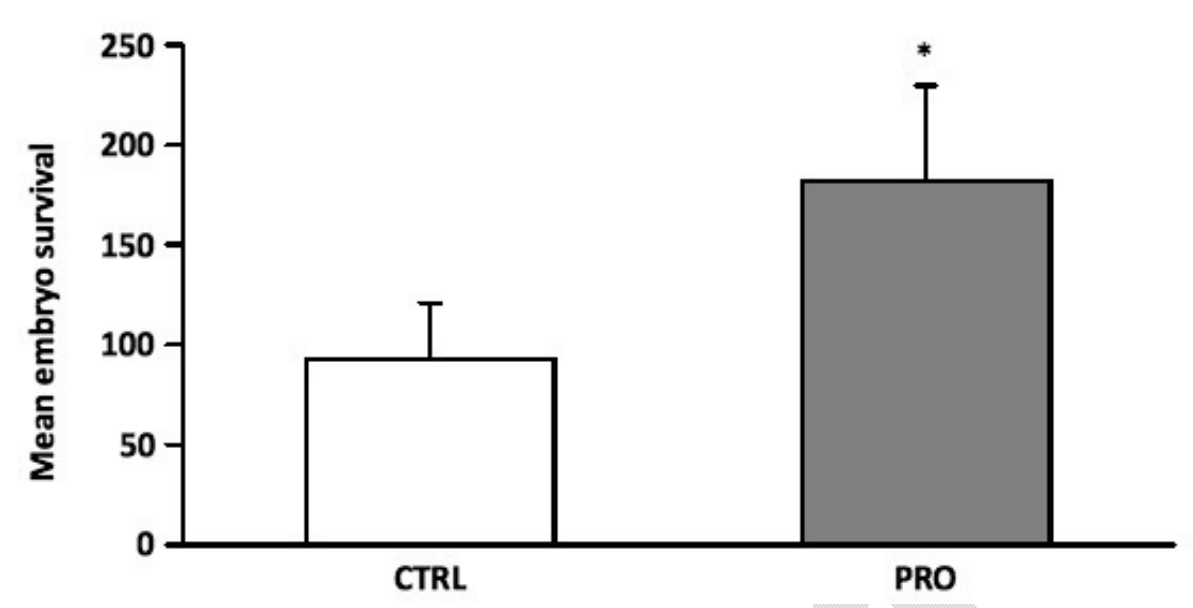

Figure 4: Killifish hatching rate. CTRL: larvae hatched from fish fed commercial diet; PRO: larvae hatched from fish fed probiotic (L. rhamnosus IM C 501@)-supplemented diet.

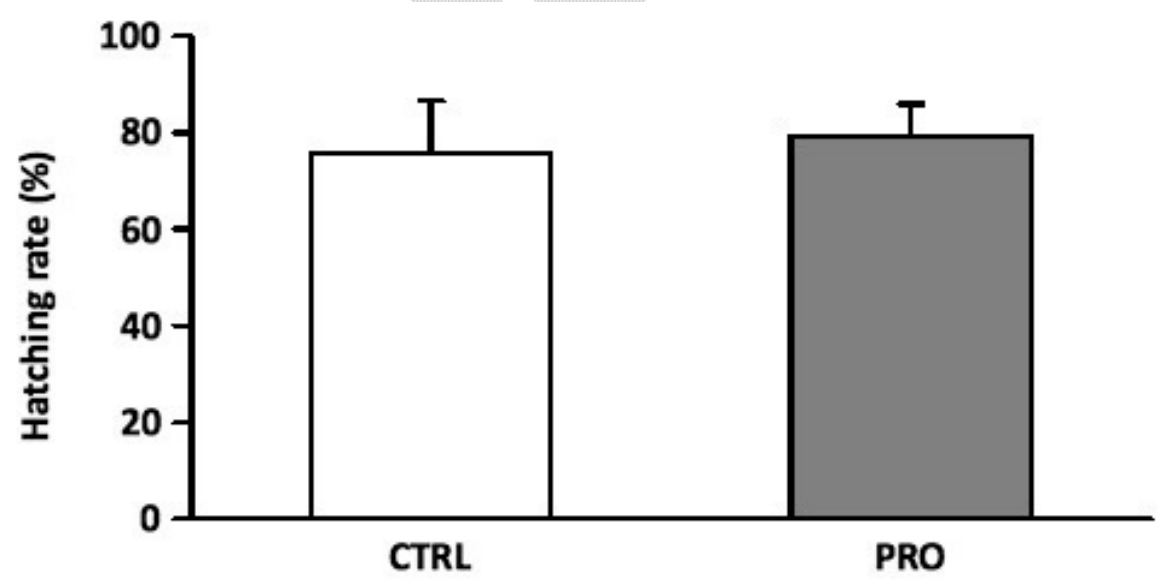

\subsection{Probiotic effects on progeny biometric parameters}

At hatching time ( $0 \mathrm{dph})$, biometric parameters showed no significant differences in terms of BW and TL among groups ( $P>0.05)$ (Figures 5 and 6$)$. However, from $10 \mathrm{dph}$ larvae hatched from PRO group showed a significantly higher TL when compared to CTRL group and the differences remained significant until the end (30 $\mathrm{dph}$ ) of the experiment $(\mathrm{P}<0.05)$ (Figure 5). Indeed, larvae hatched from the PRO group at $20 \mathrm{dph}$ had the same TL of larvae hatched from the CTRL group at $30 \mathrm{dph}$. On the other hand, measurement of BW showed a significant difference at $30 \mathrm{dph}(\mathrm{P}<0.05)$ (Figure 6), while larval survival was not affected (data not shown). 
Figure 5: M ean measurements of total length (TL) of killifish larvae. CTRL: larvae hatched from broodstocks fed control diet; PRO: larvae hatched from broodstocks fed probiotic (L. rhamnosus IM C 501 ®)-supplemented diet.

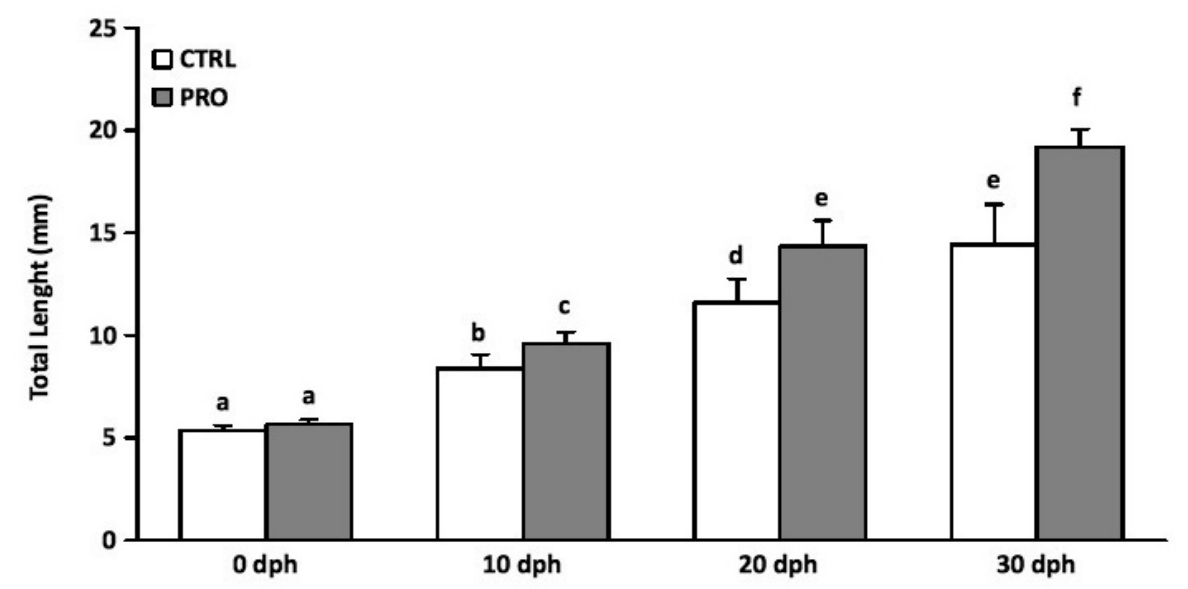

Figure 6: Mean measurements of body weight (BW) of killifish larvae. CTRL: larvae hatched from broodstocks fed control diet; PRO: larvae hatched from broodstocks fed probiotic (L. rhamnosus IM C 501@)-supplemented diet.

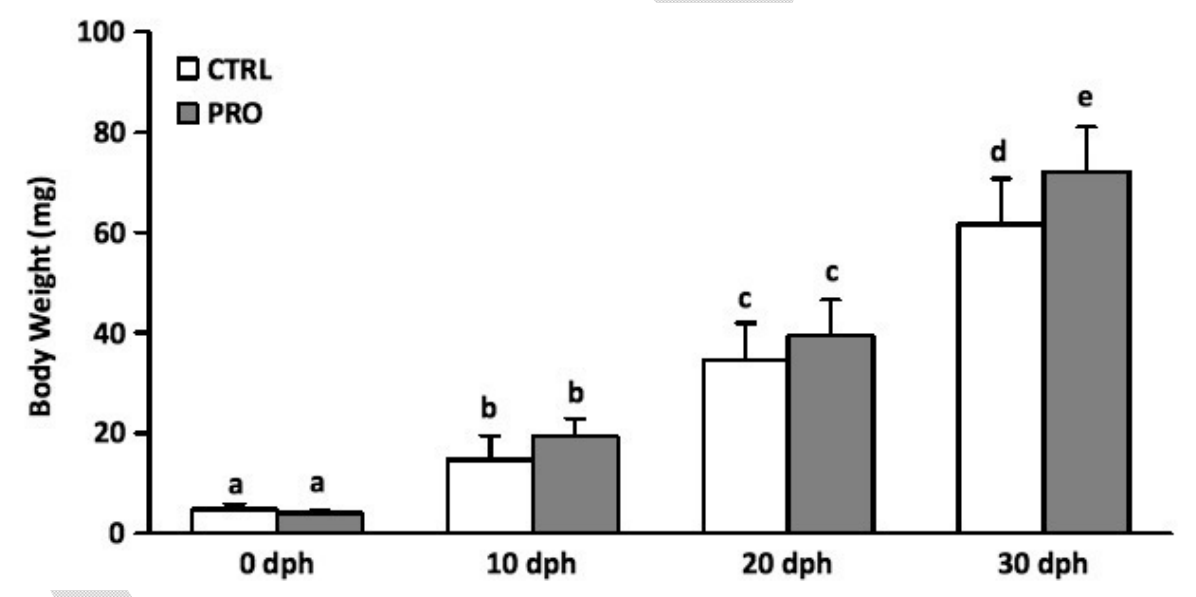

\section{Discussion}

\subsection{Probiotic effects on killifish reproduction}

Currently, as reported by Dimitroglou et al. [11], many probiotic strains are successfully utilized for growth and health management in the sustainable and environmentally-friendly aquaculture. Generally, probiotic bacteria enhance nutrition by synthesizing essential nutrients (proteins and essential fatty acids) and enzymes (amylase, protease and lipase) which increase the digestive efficacy of the complex proteins and lipids included in the diet, thus increasing the rate at which nutrients can be assimilated by the host animal $[12,19,29]$. In addition, probiotics can modify gut activity and morphology (e.g. microvilli length), as reported in rainbow trout ( 0 . mykiss) enterocytes [30]. Proteins and fatty acids are very important constituents of the yolk and their presence in the diet consequently supports both good oocyte development and maturation as well as higher vitellogenesis rate [19,31-33]. 
In this study, 8 days of feeding of dietary L. rhamnosus IM C $501 @$ improved killifish reproductive performance, increasing GSI and fecundity, probably due to the involvement of L. rhamnosus IM C 501 @in follicle growth and development. These increases may be due to the capacity of the probiotic to increase vitellogenesis and subsequently oocyte maturation, as well as modulate gene expression of neuropeptide hormones and metabolic signals both at central nervous system (CNS) and at peripheral level, as recently demonstrated in the zebra fish D. rerio [15].

Thus, the stimulatory role of L. rhamnosus IM C 501 @ on killifish reproductive performance may be due to both the activation of the neuroendocrine system that regulates reproduction and to local factors that control oocyte development and maturation.

The significant enhancement of embryo survival indicated that the beneficial health effects of $L$. rhamnosus IMC 501® probiotic are occur during embryo development, probably playing a role in the mechanisms of immunity complement system activation that is the major component of the innate immune system at this stage [34] and which serves to protect the newborn before the maturation of the immune system [35]. At the time of hatching, the lymphoid system is still developing and, unlike in adult fish, neither the organization nor the functional capabilities are displayed at this stage [36]. Thus, whether or not the fish embryo is capable of initiating a complete set of immune responses is not clear at this point, but evidence has previously been presented which shows that $1 \mathrm{dpf}$ carp (C. carpio) embryos respond to microinjection of bacterial lipopolysaccharide increasing interleukin transcript levels [37 and that gene transcriptions involved in the innate immune response are induced in the embryos of zebra fish [38]. Moreover, maternally-derived components of immunity occurring in eggs, embryos and hatchlings have also been found in rainbow trout $(0$. mykiss) [39] and killifish [40].

On this basis, and because killifish embryos were not directly exposed to probiotic, it might be assumed that $\mathrm{L}$. rhamnosus IMC $501{ }^{\circledR}$ may have also affected the embryo immune complement system activation via the maternal inheritance of appropriate metabolic information and/or immunological cues, thus helping the embryos to develop and survive. As yet, no such functional studies have been carried out, so this hypothesis must be considered only speculative and further testing is required.

\subsection{Probiotic effects on larvae growth}

The viability of fish embryos and larvae is an important topic for both aquaculture and fisheries biologists, as early embryo and larval survival of freshwater and marine fish can vary dramatically [41,42]. Probiotics are well known to positively impact fish welfare [43] by reducing the general stress response and promoting growth $[14,44-46]$ as well as increasing overall survival [47]. Several probiotic strains have been used to enhance larval survival and growth $[44,46,48]$ with several Lactobacillus strains showing beneficial effects on fish juvenile husbandry [49,50] with positive effects also on growth metabolism [14]. Moreover, early feeding with probiotic-supplemented diet stimulated the sea bass larval gut immune system and lowered transcription of key pro-inflammatory genes [51]. In addition, data regarding a sustainable aquaculture development was provided by application of multiple species of Bacillus during gilthead sea bream larviculture [46]. More recently, evidence that probiotic treatment can modulate neuroendocrine system responses during the larval rearing of the flatfish sole (Solea solea) has also been reported [52].

The higher BW and TL observed during larval stages, in the present study, suggest that the beneficial effects of probiotic, maternally transferred to the embryo, were useful in accelerating early embryo development in killifish and continue to exert its positive effects during larval development in this species.

\section{Conclusion}

In the present study, the potentially beneficial effects of L. rhamnosus IM C $501 @$ on killifish reproduction was assessed by analysing reproductive performance parameters as GSI, fecundity, and embryo survival, and the results suggest a functional role of $\mathrm{L}$. rhamnosus IM C 501 @in the reproductive enhancement of this species, via the acceleration of early embryo development as well as exerting positive effects during larval development.

These results can assist in laying the groundwork for future research in the field of nutritionally/immunologically-mediated maternal effects both on embryo and larval development and growth. The 


\section{Research Article}

question of whether these improved growth performances are derived from enhanced broodstock nutrition and thus from such nutritionally-/immunologically-mediated maternal effects will be addressed in future studies.

\section{Competing Interests}

This work was financially supported by Fondi di Ateneo 2009 to Oliana Carnevali. The authors declare that they do not have any competing interests with the publication of this work.

\section{Authors' Contributions}

Oliana Carnevali, Francesco Lombardo and Giorgia Gioacchini: conceived and designed the experiments. Francesco Lombardo: performed the experiments.

Francesco Lombardo, Giorgia Gioacchini and Oliana Carnevali: analysed the data.

Oliana Carnevali: contributed/reagents/materials/analysis tools.

Francesco Lombardo and Oliana Carnevali: wrote the paper.

Giorgia Gioacchini: revised the paper.

\section{Acknowledgement}

The authors are grateful to Synbiotec S.r.l. for providing probiotic strain and OceAN soc coop for the technical support at the facilities.

\section{References}

[1] Tena-Sempere M, Huhtaniemi IT, 2003. Gonadotropins and gonadotropin receptors. In Reproductive Medicine. Molecular, Cellular and Genetic Fundamentals. Edited by Fauser BCJM. New York: Parthenon Publishing, 225-244.

[2] Fernández-Fernández R, Tena-Sempere M, Navarro VM, et al., 2006. Effects of ghrelin upon gonadotropinreleasing hormone and gonadotropin secretion in adult female rats: in vivo and in vitro studies. Neuroendocrinology, 82: 245-255.

[3] Scaramuzzi RJ, Campbell BK, Downing JA, et al., 2006. A review of the effects of supplementary nutrition in the ewe on the concentrations of reproductive and metabolic hormones and the mechanisms that regulate folliculogenesis and ovulation rate. Reproduction, Nutrition, Development, 46(4): 339-354.

[4] Izquierdo MS, Fernández-Palacios H, Tacon AG], 2001. Effect of broodstock nutrition on reproductive performance of fish. Aquaculture, 197: 25-42.

[5] Lara-Flores M, Olvera-Novoa MA, Guzmán-Méndez BE, et al., 2003. Use of the bacteria Streptococcus faecium and Lactobacillus acidophilus, and the yeast Saccharomyces cerevisiae as growth promoters in Nile tilapia (Oreochromis niloticus). Aquaculture, 216: 193-201.

[6] Austin B, Stuckey LF, Robertson PAW, et al., 1995. A probiotic strain of Vibrio alginolyticus effective in reducing diseases caused by Aeromonas salmonicida, Vibrio anguillarum and Vibrio ordalii. Journal of Fish Diseases, 18(1): 93-96.

[7] Akinbowale OL, Peng H, Barton MD, 2006. Antimicrobial resistance in bacteria isolated from aquaculture sources in Australia. Journal of Applied M icrobiology, 100: 1103-1113.

[8] van der Waaij D, Nord CE, 2000. Development and persistence of multi-resistance to antibiotics in bacteria: an analysis and a new approach to this urgent problem. International Journal of Antimicrobial Agents, 16: 191-197. 
[9] Bengmark S, 1998. Ecological control of the gastrointestinal tract. The role of probiotic flora. Gut, 42: 2-7.

[10] FAO/WHO, 2001. Guidelines for the evaluation of probiotics in food. FAO and WHO Working Group Report, pp. 11.

[11] Dimitroglou A, M errifield DL, Carnevali O, et al., 2011. Microbial manipulations to improve fish health and production - A M editerranean perspective. Fish \& Shellfish Immunology, 30: 1-16.

[12] Gatesoupe FJ, 1999. The use of probiotics in aquaculture. Aquaculture, 180: 147-165.

[13] Carnevali 0, Zamponi MC, Sulpizio R, et al., 2004. Administration of probiotic strain to improve sea bream wellness during development. Aquaculture International, 12: 377-386.

[14] Carnevali O, De Vivo L, Sulpizio R, et al., 2006. Growth improvement by probiotic in European sea bass juveniles (Dicentrarchus labrax L.), with particular attention to IGF-1, myostatin and cortisol gene expression. Aquaculture, 258: 430-438.

[15] Gioacchini G, M aradonna F, Lombardo F, et al., 2010. Increase of fecundity by probiotic administration in zebrafish (Danio rerio). Reproduction, 140: 953-959.

[16] Raida M K, Larsen JL, Nielsen ME, et al., 2003. Enhanced resistance of rainbow trout, Oncorhynchus mykiss (Walbaum), against Yersinia ruckeri challenge following oral administration of Bacillus subtilis and $B$. licheniformis (Bio-Plus2B). Journal of Fish Disease, 26: 495-498.

[17] Salinas I, Cuesta A, Esteban MÁ, et al., 2005. Dietary administration of Lactobacillus delbrüeckii and Bacillus subtilis, single or combined, on gilthead seabream cellular innate immune responses. Fish \& Shellfish Immunology, 19: 67-77.

[18] Balcázar JL, de Blas I, Ruiz-Zarzuela I, et al., 2006. The role of probiotics in aquaculture. Veterinary Microbiology, 114: 173-186.

[19] Ghosh S, Sinha A, Sahu C, 2007. Effect of probiotic on reproductive performance in female livebearing ornamental fish. Aquaculture Research, 38: 518-526.

[20] Abasali H, Mohamad S, 2010. Effect of dietary supplementation with probiotic on reproductive performance of female livebearing ornamental fish. Journal of Aquaculture Feed Science and Nutrition, 2(24): 11-15.

[21] Abasali H, M ohamad S, 2011. Effect of dietary probiotic level on the reproductive performance of female platy Xiphophorus maculatus. Agricultural Journal, 6(3): 119-123.

[22] Taylor MH, 1986. Environmental and endocrine influences on reproduction of Fundulus heteroclitus. American Zoologist, 26: 159-171.

[23] Taylor MH, DiM ichele L, 1980. Ovarian changes during the lunar spawning cycle of Fundulus heteroclitus. Copeia, 1: 118-125.

[24] Hsiao SM, Limesand S, Wallace RA, 1996. Semilunar follicular cycle of an intertidal fish: the Fundulus model. Biology of Reproduction, 54: 809-818.

[25] Shimizu A, 2003. Effect of photoperiod and temperature on gonadal activity and plasma steroid levels in a reared strain of the mummichog (Fundulus heteroclitus) during different phases of its annual reproductive cycle. General and Comparative Endocrinology, 131: 310-324.

[26] M anley KJ, Fraenkel M B, M ayall BC, et al., 2007. Probiotic treatment of vancomycin-resistant enterococci: a randomised controlled trial. M edical Journal of Australia, 186: 454-457. 
[27] Pant $N$, Marcotte $H$, Brussow $H$, et al., 2007. Effective prophylaxis against rotavirus diarrhea using a combination of Lactobacillus rhamnosus GG and antibodies. BM C Microbiology, 7: 86-89.

[28] Verdenelli MC, Ghelfi F, Silvi S, et al., 2009. Probiotic properties of Lactobacillus rhamnosus and Lactobacillus paracasei isolated from human faeces. European Journal of Nutrition, 48: 355-363.

[29] Irianto A, Austin B, 2002. Probiotics in aquaculture. Journal of Fish Diseases, 25: 633-642.

[30] M errifeld DL, Harper GM , Dimitroglou A, et al., 2010. Possible influence of probiotic adhesion to intestinal mucosa on the activity and morphology of rainbow trout (Oncorhynchus mykiss) enterocytes. Aquaculture Research, 41: 1268-1272.

[31] Shim KF, Landesman L, Lam TJ, 1989. Effect of dietary protein on growth ovarian development and fecundity in the dwarf gourami Colisa lalia (Hamilton). Journal of Aquaculture in the Tropics, 4: 111-123.

[32] Carnevali O, M osconi G, Centonze F, et al., 1998. Influence of diet on yolk protein components in sea bass, Dicentrarchus labrax. Scientia Marina, 62(4): 311-318.

[33] Carnevali O, Mosconi G, Roncarati A, et al., 1993. Yolk protein changes dying oocyte growth in European sea bass Dicentrarchus labrax. Journal of Applied Ichthyology, 9(3-4): 175-184.

[34] M organ BP, M archbank KJ, Longhi MP, et al., 2005. Complement: central to innate immunity and bridging to adaptive responses. Immunology Letters, 97: 171-179.

[35] Ogundele MO, 2001. Role and significance of the complement system in mucosal immunity: particular reference to the human breast milk complement. Immunology and Cell Biology, 79: 1-10.

[36] Ellis AE, 1988. Ontogeny of the immune system in teleost fish. In: Fish vaccination, Edited by Ellis AE. London: Academic Press, 20-31.

[37] Rombout JHWM , Huttenhuis HBT, Picchietti S, et al., 2005. Phylogeny and ontogeny of fish leucocytes. Fish \& Shellfish Immunology, 19: 441-455.

[38] Watzke J, Schirmer K, Scholz S, 2007. Bacterial lipopolysaccharides induce genes involved in the innate immune response in embryos of the zebrafish (Danio rerio). Fish \& Shellfish Immunology, 23: 901-905.

[39] Løvoll M, Kilvik T, Boshra H, et al., 2006. Maternal transfer of complement components C3-1, C3-3, C3-4, C4, C5, C7, Bf, and Df to offspring in rainbow trout (Oncorhynchus mykiss). Immunogenetics, 58: 168-179.

[40] Hunt LR, 2007. The estuarine killifish, Fundulus heteroclitus, as a model system for developmental immunotoxicology. PhD thesis. Clemson University.

[41] Bromage N, Jones J, Randall C, et al., 1992. Broodstock management, fecundity, egg quality and timing of egg production in the rainbow trout (Oncorhynchus mykiss). Aquaculture, 100: 141-166.

[42] Nagler JJ, Adams BA, Cyr DG, 1999. Egg production, fertility and hatch success of American plaice held in captivity. Transactions of the American Fisheries Society, 128(4): 727-736.

[43] Kesarcodi-Watson A, Kaspar H, Lategan MJ, et al., 2008. Probiotics in aquaculture: the need, principles and mechanisms of action and screening processes. Aquaculture, 274: 1-14.

[44] Suzer C, Çoban D, Kamaci HO, et al., 2008. Lactobacillus spp. bacteria as probiotics in gilthead sea bream (Sparus aurata, L.) larvae: effects on growth performance and digestive enzyme activities. Aquaculture, 280: 140-145.

[45] Rollo A, Sulpizio R, Nardi M, et al., 2006. Live microbial feed supplement in aquaculture for improvement of stress tolerance. Fish Physiology and Biochemistry, 32: 167-177. 
[46] Avella AM, Gioacchini G, Decamp 0, et al., 2010. Application of multi-species of Bacillus in sea bream larviculture. Aquaculture, 305: 12-19.

[47] Wang Y, Li J, Lin J, 2008. Probiotics in aquaculture: challenges and outlook. Aquaculture, 281: 1-4.

[48] Tovar-Ramírez D, Zambonino Infante J, Cahu C, et al., 2004. Influence of dietary live yeast on European sea bass (Dicentrarchus labrax) larval development. Aquaculture, 234: 415-427.

[49] Balcázar JL, de Blas I, Ruiz-Zarzuela I, et al., 2007. Changes in intestinal microbiota and humoral immune response following probiotic administration in brown trout (Salmo trutta). British Journal of Nutrition, 97: 522-527.

[50] Balcázar JL, de Blas I, Ruiz-Zarzuela I, et al., 2007. Enhancement of the immune response and protection induced by probiotic lactic acid bacteria against furunculosis in rainbow trout (Oncorhynchus mykiss). FEMS Immunology and Medical Microbiology, 51: 185-193.

[51] Picchietti S, Fausto AM, Randelli E, et al., 2009. Early treatment with Lactobacillus delbrüeckii strain induces an increase in intestinal T-cells and granulocytes and modulates immune-related genes of larval Dicentrarchus labrax (L.). Fish \& Shellfish Immunology, 26: 368-376.

[52] Palermo FA, M osconi G, Avella MA, et al., 2011. Modulation of cortisol levels, endocannabinoid receptor $1 \mathrm{~A}$, proopiomelanocortin and thyroid hormone receptor alpha mRNA expressions by probiotics during sole (Solea solea) larval development. General and Comparative Endocrinology, 171: 293-300. 